\title{
Elevated triglyceride-to-HDL cholesterol ratio is an indicator for insulin resistance in middle-aged and elderly Taiwanese population: a cross-sectional study
}

Wei-Chung Yeh ${ }^{1}$, Yu-Chung Tsao ${ }^{1,2,3}$, Wen-Cheng Li ${ }^{1,4}$, I-Shiang Tzeng ${ }^{5}$, Liang-Sien Chen ${ }^{1}$ and Jau-Yuan Chen ${ }^{1,2^{*}}$ (D)

\begin{abstract}
Background: Previous studies have reported that the triglyceride to high-density lipoprotein cholesterol (TG/HDLC) ratio could be a simple clinical indicator of insulin resistance (IR), but the results indicated that there were heterogeneities between different ethnicities. We aimed to investigate the association between TG/HDL-C and IR (as measured by homeostasis model assessment of IR [HOMA-IR]), and establish a clinical prediction rule for IR in middle-aged and elderly Taiwanese.
\end{abstract}

Methods: A total of 398 subjects were recruited, and each subject completed a questionnaire that included personal and medical history data, and underwent anthropometric measurement and blood sampling. IR was defined as HOMA-IR index value $\geq 2.0$. Chi-squared test, independent two-sample t-test, Pearson's correlation coefficient, and multiple logistic regression were used to evaluate the association between IR and TG/HDL-C ratio. A receiver operating characteristic $(\mathrm{ROC})$ analysis was conducted to evaluate the ability of the developed clinical prediction rule to correctly discriminate between subjects of IR positive and IR negative groups.

Results: A significant association between IR and TG/HDL-C ratio was identified with a Pearson's correlation coefficient of 0.35 ( $p$-value< 0.001). In multiple logistic regression, high BMI $(\mathrm{OR}=1.23 ; 95 \%$ C.I. $=1.13-1.33)$, hypertension $(\mathrm{OR}=1.90 ; 95 \% \mathrm{C.I} .=1.12-3.21)$, diabetes mellitus $(\mathrm{OR}=5.44 ; 95 \% \mathrm{C.I}=2.93-10.08)$ and high TG/HDL ratio $(\mathrm{OR}=1.45 ; 95 \% \mathrm{C.I}=1.23-1.72)$ were significantly associated with the risk of elevated HOMA-IR.

The area under ROC curves for TG/HDL-C ratio was 0.729 and the optimal threshold value was 2.197 where the corresponding of sensitivity and specificity were 72.4 and $65.1 \%$.

Conclusions: Our findings showed that the elevated TG/HDL-C ratio was significantly associated with IR and could be used as an indicator of IR among the middle-aged and elderly population in Taiwan. It is clinically available, thus eliminating any additional costs. Future research is warranted to investigate the use of TG/HDL-C ratio combined with other risk factors for predicting IR under diverse ethnic backgrounds.

Keywords: Anthropometry, Body fat; insulin resistance, Prediction, Triglyceride to high-density lipoprotein cholesterol ratio

\footnotetext{
* Correspondence: welins@cgmh.org.tw

${ }^{1}$ Department of Family Medicine, Chang-Gung Memorial Hospital, Linkou

Branch, Postal address: No. 5, Fuxing St., Guishan Dist, Taoyuan City 33305,

Taiwan, Republic of China

${ }^{2}$ Chang Gung University College of Medicine, No.259, Wenhua 1st Rd.,

Guishan Dist., Taoyuan City 333, Taiwan, Republic of China

Full list of author information is available at the end of the article
}

(c) The Author(s). 2019 Open Access This article is distributed under the terms of the Creative Commons Attribution 4.0 International License (http://creativecommons.org/licenses/by/4.0/), which permits unrestricted use, distribution, and reproduction in any medium, provided you give appropriate credit to the original author(s) and the source, provide a link to the Creative Commons license, and indicate if changes were made. The Creative Commons Public Domain Dedication waiver (http://creativecommons.org/publicdomain/zero/1.0/) applies to the data made available in this article, unless otherwise stated. 


\section{Background}

Insulin resistance (IR), the most common feature of obesity, is a major pathophysiological factor in the development and progression of diabetes mellitus (DM) and cardiovascular disease [1-4]. Currently, several directly and indirectly methods for assessing IR are available [5]. Among them, the gold standard method is the hyperinsulinemic euglycemic clamp test (HEC test), originally developed by DeFronzo [6]. However, the method is expensive, invasive, and time-consuming, making it not feasible for either epidemiological investigations or routine clinical applications [7]. Therefore, the homeostasis model assessment of IR (HOMA-IR) has emerged to evaluate IR [6, 8].

The lack of standardized insulin assay has limited the clinical utility of HOMA-IR, although it has been widely used in the study of metabolic syndrome [9]. Additionally, the HOMA-IR is not routinely measured in clinical practice when used for quantifying IR. In a clinical perspective, a simple and more accessible marker for predicting IR can be useful for early identification of subjects with IR for clinicians and eliminate any additional costs.

Some evidences have indicated that hypertriglyceridemia and low high-density lipoprotein cholesterol are two key metabolic abnormalities associated with IR states $[10,11]$. Previous studies have shown that the triglyceride to high-density lipoprotein cholesterol (TG/ HDL-C) concentration ratio is closely related to IR [12, 13]. In these studies, TG/HDL-C ratio has been identified as a simple clinical indicator of IR and a predictor of diabetes [14] and coronary heart disease [15].

Recently, the TG/HDL-C ratio has been investigated for various potential clinical uses in adult and pediatric populations $[13,16-26]$. Thus, it seems to help clinicians identify IR persons by using the TG/HDL-C ratio, based on commonly available and standardized measurements. While using the TG/HDL-C ratio to identify IR, it should be noted that the relationship between TG/HDL$\mathrm{C}$ and insulin may differ by ethnicity. It means that the results may be heterogeneity between different ethnicities. Hence, using TG/HDL-C to predict IR would not be appropriate in certain populations $[27,28]$. Moreover, few studies have predicted IR by using TG/HDL-C among a middle-aged and elderly population in Taiwan.

This study was conducted to investigate the association between TG/HDL-C and IR (as measured by HOMA-IR) and to establish a clinical prediction rule for IR through the marker, TG/HDL-C ratio, among a middle-aged and elderly population in Taiwan.

\section{Methods}

\section{Study design and study population}

Participants in this study were recruited from a community health promotion project of Linkou Chang Gung
Memorial Hospital between February 2014 and August 2014. In total, 400 participants aged 50 years or over were recruited through posters and advertisements from the community office.

This study was approved by the Chang Gung Medical Foundation Institutional Review Board and written informed consent form was given by all participants before enrollment. A questionnaire that included personal information and medical history was completed through a face-to-face interview for each participant. Participants with incomplete or missing data were excluded. The final number of participants was 398.

\section{Anthropometric and laboratory examinations}

Information on demographic including age, sex was collected after obtaining informed consent. WC was measured at the level midway between the iliac crest and the lower border of the 12th rib. Body mass index (BMI) was calculated as weight divided by the square of the height $\left(\mathrm{kg} / \mathrm{m}^{2}\right)$.

Blood sampling were conducted by trained nurses. Participants were requested to fast for a minimum of 12 $h$ and to avoid a high-fat diet or alcohol consumption before blood sampling. Venous blood samples were stored in a refrigerator at $4{ }^{\circ} \mathrm{C}$ prior to analysis in the hospital laboratory. TG, total cholesterol, HDL-C, lowdensity lipoprotein cholesterol (LDL-C), glucose, insulin, fasting plasma glucose (FPG), and alanine aminotransferase (ALT) were measured using blood sample collected from each participant in a hospital laboratory accredited by the College of American Pathologists.

\section{Diagnosis of insulin resistance}

HOMA-IR was calculated by fasting glucose (in $\mathrm{mmol} / \mathrm{L}$ ) $\times$ fasting insulin (in $\mathrm{mU} / \mathrm{ml}$ ) $/ 22.5$ [29]. In a study of 2649 Chinese subjects, the HOMA-IR cut-off value to identify diabetes was 1.97 as determined by the receiver-operating characteristic (ROC) curve, and 2.03 in the 90th percentile of subjects with normal glucose tolerance [30].

Because most Taiwanese ancestors emigrated from China hundred years ago, we defined IR as $\geq 2$ in our study.

\section{Statistical analysis}

Statistical analyses were performed using SPSS version 22 software (IBM, SPSS Armonk, NY, IMM Corp). A two-sided $p$-value $<0.05$ was considered as statistical significance. Participants were divided into IR positive and IR negative groups using a cut-off value of 2 . Continuous variables were expressed as mean and standard deviation, and categorical variables were represented by counts and percentages. Differences in demographic and clinical characteristics of participants in each group were 
compared using independent two-sample t-test for continuous data and chi-square test for categorical data. Pearson's correlation coefficient was calculated for the correlations between cardiovascular disease risk factors and IR.

Multiple logistic regression analysis was conducted to evaluate other covariates that were significantly associated with IR in addition to TG/HDL-C. A ROC analysis was conducted to evaluate the ability of the established model for correctly discriminating the participants of IR positive and IR negative. The ROC curves for the established model was made and the overall diagnostic accuracy was quantified using the area under the ROC curve (AUC). The optimal cutoff points were determined by the Youden's index, and the corresponding sensitivity and specificity were calculated.

\section{Results}

\section{Descriptive statistics}

A total of 400 participants were recruited through posters and advertisements from the community office. Two people were excluded for extreme values, incomplete or missing data. Finally, 398 participants were enrolled in this study.

Table 1 shows the general demographic and characteristics of participants according to IR positive and IR negative that categorized by HOMA-IR using a cut-off value of 2 . The subjects comprised of 139 males (35\%) and 259 females (65\%), with an overall mean age of $64.43 \pm 8.45$ years. The average BMI and WC were $24.54 \pm 3.57\left(\mathrm{~kg} / \mathrm{m}^{2}\right)$ and $84.99 \pm 9.62 \mathrm{~cm}$, respectively. The mean HOMA-IR index was $1.86 \pm 1.39$ and the mean TG/HDL-C ratio was $2.52 \pm 1.83$. There were no significantly differences in age, creatinine, percentage of current smoking, alcohol drinking, and vegetarian between IR positive and IR negative groups. The IR positive group had higher blood pressure, BMI, waist circumference, fasting glucose and TG/HDL-C ratio than the IR negative group.

\section{Correlation analysis}

Table 2 shows the correlations between different anthropometric indices and HOMA-IR with and without adjusting for age. The variables including BMI, waist circumference, fasting glucose, TG, and TG/HDL-C were statistically significantly positively associated with HOMA-IR before and after adjusting for age. The variable, HDL-C, was statistically significantly negatively associated with HOMA-IR. Figure 1 demonstrates the positive correlation between TG/HDL-C and HOMA-IR index with a Pearson's correlation coefficient of 0.35 .

\section{Multivariable analysis}

Table 3 shows the four models of the association between TG/HDL-C and HOMA-IR index adjusting for related covariates through multiple logistic regression analyses. In Model 1, the odds ratios (OR) were calculated after adjusting for sex. In Model 2, the OR were calculated after adjusting for sex, age and BMI. In Model 3, we examined the relationship between TG/HDL and IR after adjusting for additional confounding variables such as hypertension (HTN), DM and hyperlipidemia. In Model 4, we adjusted for sex, age, BMI, current smoking status, HTN, DM and hyperlipidemia. In Model 1, an increase of 1 unit in the TG/HDL-C ratio was associated with an elevation in the IR by $59 \%$, while in Model 2-4, the corresponding in the TG/HDL-C ratio was associated with 48,45 , and $45 \%$ elevation in the odds, respectively. In Model 4 (the final model), BMI (adjusted OR [aOR]: $1.23 ; 95 \%$ confidence interval [C.I.]: 1.13-1.33; $p$ value< 0.001 ), HTN (aOR: 1.90, 95\% C.I.: 1.12-3.21; $p$-value <0.05), DM (aOR: 5.44, 95\% C.I.: 2.93-10.08; $p$-value <0.001), and TG/HDL-C (aOR: 1.45, 95\% C.I.: $1.23-1.72 ; p$-value $<0.001)$ were all significantly associated with HOMA-IR index.

\section{ROC analysis}

Figure 2 shows the ROC curve for TG/HDL-C as a predictor for HOMA-IR index. The AUC of TG/HDL-C for predicting HOMA-IR index was 0.729, which was significant, with a $p$-value lower than 0.001 , as shown in Table 4 . The optimal cut-off point calculated by the Youden's index for using the TG/HDL-C ratio to predict HOMA-IR index was 2.197 where the corresponding sensitivity and specificity were 72.4 and $65.1 \%$, respectively.

\section{Discussion}

The current findings of the study indicate that the TG/ HDL-C ratio is strongly associated with IR (as measured by HOMA-IR) in middle-aged and elderly Taiwanese. A high value of TG/HDL-C ratio was positively related to HOMA-IR after adjusting for potential confounding variables. TG/HDL-C ratio was significantly higher in subjects with HOMA-IR index $\geq 2$ (IR positive) as compared to those with HOMA-IR index $<2$ (IR negative). The results showed that using the TG/HDL-C ratio to detect IR was valid.

The mechanism of high TG and low HDL is adipose tissue trap and retains less fatty acid in IR status. Thus, increased free fatty acid was transported to liver to synthesize more TG and TG containing very low-density lipoproteins (VLDL). Besides, the TG of TG containing VLDL and the cholesteryl ester of HDL exchange as the plasma TG concentration increases. This action forms the TG-rich HDL that is 
Table 1 General characteristics of the study population according to IR positive and IR negative

\begin{tabular}{|c|c|c|c|c|c|c|c|}
\hline \multirow[t]{3}{*}{ Variables } & \multicolumn{7}{|c|}{ Insulin Resistance } \\
\hline & \multirow{2}{*}{$\frac{\text { Total }}{(n=398)}$} & & \multicolumn{2}{|c|}{ IR positive } & \multicolumn{2}{|c|}{ IR negative } & \multirow[b]{2}{*}{$p$-value } \\
\hline & & & $(n=123)$ & $(\geqq 2)$ & $(n=275)$ & $(<2)$ & \\
\hline Age (year) & 64.43 & \pm 8.45 & 64.59 & \pm 7.86 & 64.36 & \pm 8.71 & 0.80 \\
\hline SBP $(\mathrm{mmHg})$ & 129.57 & \pm 16.72 & 133.97 & \pm 16.49 & 127.60 & \pm 16.47 & $<0.001$ \\
\hline $\mathrm{DBP}(\mathrm{mmHg})$ & 76.94 & \pm 11.36 & 78.91 & \pm 10.66 & 76.06 & \pm 11.57 & 0.02 \\
\hline BMI $\left(\mathrm{kg} / \mathrm{m}^{2}\right)$ & 24.54 & \pm 3.57 & 26.43 & \pm 3.69 & 23.70 & \pm 3.18 & $<0.001$ \\
\hline Waist circumference $(\mathrm{cm})$ & 84.99 & \pm 9.62 & 90.51 & \pm 9.86 & 82.53 & \pm 8.43 & $<0.001$ \\
\hline $\operatorname{ALT}(\mathrm{U} / \mathrm{L})$ & 22.66 & \pm 12.97 & 27.28 & \pm 17.01 & 20.60 & \pm 10.06 & $<0.001$ \\
\hline Creatinine (mg/dL) & 0.77 & \pm 0.42 & 0.78 & \pm 0.33 & 0.77 & \pm 0.45 & 0.88 \\
\hline $\operatorname{eGFR}\left(\mathrm{ml} / \mathrm{min} / 1.73 \mathrm{~m}^{2}\right)$ & 113.25 & \pm 33.21 & 109.95 & \pm 31.90 & 114.73 & \pm 33.73 & 0.19 \\
\hline FPG (mg/dL) & 95.54 & \pm 22.32 & 110.06 & \pm 31.81 & 89.05 & \pm 11.59 & $<0.001$ \\
\hline $\mathrm{HDL}-\mathrm{C}(\mathrm{mg} / \mathrm{dL})$ & 54.51 & \pm 13.91 & 48.68 & \pm 11.37 & 57.12 & \pm 14.17 & $<0.001$ \\
\hline HOMA-IR index & 1.86 & \pm 1.39 & 3.39 & \pm 1.58 & 1.18 & \pm 0.44 & $<0.001$ \\
\hline LDL-C (mg/dL) & 118.47 & \pm 32.16 & 112.11 & \pm 29.83 & 121.31 & \pm 32.80 & 0.01 \\
\hline Total Cholesterol (mg/dL) & 197.19 & \pm 35.69 & 191.46 & \pm 34.08 & 119.75 & \pm 36.16 & 0.03 \\
\hline $\mathrm{TG} / \mathrm{HDL}$ & 2.52 & \pm 1.83 & 3.48 & \pm 2.32 & 2.09 & \pm 1.37 & $<0.001$ \\
\hline Triglyceride (mg/dL) & 121.20 & \pm 62.93 & 153.46 & \pm 76.04 & 106.77 & \pm 49.88 & $<0.001$ \\
\hline Uric Acid (mg/dL) & 5.74 & \pm 1.41 & 6.10 & \pm 1.36 & 5.58 & \pm 1.41 & 0.001 \\
\hline WBC (1000/uL) & 6.04 & \pm 1.59 & 6.71 & \pm 1.79 & 5.74 & \pm 1.39 & $<0.001$ \\
\hline Men, $\mathrm{n}(\%)$ & 139 & $(34.9)$ & 41 & $(33.3)$ & 98 & $(35.6)$ & 0.66 \\
\hline Current smoking, n(\%) & 42 & $(10.6)$ & 12 & $(9.8)$ & 30 & $(10.9)$ & 0.73 \\
\hline Alcohol drinking $\geqq 2$ times/week, $n(\%)$ & 75 & $(18.8)$ & 17 & $(13.8)$ & 58 & $(21.1)$ & 0.09 \\
\hline Regular exercise, $\mathrm{n}(\%)$ & 326 & $(81.9)$ & 92 & $(74.8)$ & 234 & $(85.1)$ & 0.01 \\
\hline Vegetarian, n(\%) & 22 & $(5.5)$ & 5 & $(4.1)$ & 17 & $(6.2)$ & 0.39 \\
\hline$A C R \geqq 30 \mathrm{mg} / \mathrm{g}, \mathrm{n}(\%)$ & 74 & $(18.6)$ & 31 & $(25.2)$ & 43 & $(15.6)$ & 0.02 \\
\hline HTN, n(\%) & 199 & $(50.0)$ & 84 & $(68.3)$ & 115 & $(41.8)$ & $<0.001$ \\
\hline $\mathrm{DM}, \mathrm{n}(\%)$ & 77 & $(19.3)$ & 48 & $(39.0)$ & 29 & $(10.5)$ & $<0.001$ \\
\hline Hyperlipidemia, n(\%) & 259 & $(65.1)$ & 93 & $(75.6)$ & 166 & $(60.4)$ & 0.003 \\
\hline Metabolic syndrome & 141 & $(35.4)$ & 89 & $(72.4)$ & 52 & (18.9) & $<0.001$ \\
\hline
\end{tabular}

Notes: Clinical characteristics are expressed as mean \pm SD for continuous variables and $\mathrm{n}(\%)$ for categorical variables. P-value were derived from independent two-sample $t$-test for continuous variables and chi-square test for categorical variables

Abbreviations: SBP systolic blood pressure; DBP diastolic blood pressure; BMI body mass index; eGFR estimated glomerular filtration rate; FPG fasting plasma glucose; HDL-C high-density lipoprotein cholesterol; $L D L-C$ low-density lipoprotein cholesterol; WBC white blood cell count; ACR albumin to creatinine ratio; HTN hypertension; DM diabetes mellitus

easily catabolized. Therefore, high TG, high TG/HDL, and low HDL were observed in IR patients [31].

Additionally, the AUC value of the TG/HDL-C ratio to predict IR (as measured by HOMA-IR) was 0.729, where AUC $\geq 0.7$ is generally considered acceptable test performance. The optimal threshold was 2.197 with a corresponding sensitivity and specificity of 72.4 and 65.1\%. We considered that TG/HDL-C is an acceptable marker that can be used alone for IR assessment in middle-aged and elderly Taiwanese. A study of 812 Taiwanese adults [32] reported that the AUC of the models including TG/HDL-C ratio, sex, greater waist circumferences, and higher ALT levels was 0.71 without cut-off set. The performance of their models was similar to ours, and they were all conducted in Taiwanese adults.

Previous studies had reported different cut-off values of TG/HDL-C ratio to detect the presence of IR. The results of the cut-off values were inconsistent among different ethnic groups. A cross-sectional study of 258 subjects was the first to suggest using the TG/ HDL-C ratio as a predictor of IR. In that study, it reported that a cut-off value of TG/HDL-C ratio of 3.0 could reliably predict IR in overweight people [13]. 
Table 2 The correlation between HOMA-IR index and cardiovascular disease risk factors

\begin{tabular}{|c|c|c|c|c|}
\hline \multirow[t]{3}{*}{ Variables } & \multicolumn{4}{|c|}{ HOMA-IR index $(n=398)$} \\
\hline & \multicolumn{2}{|l|}{ Unadjusted } & \multicolumn{2}{|l|}{ Adjusted for age } \\
\hline & Pearson's coefficient & $p$-value & Pearson's coefficient & $p$-value \\
\hline Age (year) & 0.02 & 0.70 & NA & NA \\
\hline SBP $(\mathrm{mmHg})$ & 0.17 & 0.001 & 0.17 & 0.001 \\
\hline DBP (mmHg) & 0.09 & 0.079 & 0.10 & 0.06 \\
\hline BMI $\left(\mathrm{kg} / \mathrm{m}^{2}\right)$ & 0.43 & $<0.001$ & 0.433 & $<0.001$ \\
\hline Waist circumference $(\mathrm{cm})$ & 0.41 & $<0.001$ & 0.41 & $<0.001$ \\
\hline FPG (mg/dL) & 0.50 & $<0.001$ & 0.50 & $<0.001$ \\
\hline $\mathrm{HDL}-\mathrm{C}(\mathrm{mg} / \mathrm{dL})$ & -0.31 & $<0.001$ & -0.31 & $<0.001$ \\
\hline LDL-C (mg/dL) & -0.10 & 0.06 & -0.09 & 0.06 \\
\hline $\mathrm{TG}(\mathrm{mg} / \mathrm{dL})$ & 0.33 & $<0.001$ & 0.33 & $<0.001$ \\
\hline TG/HDL & 0.35 & $<0.001$ & 0.35 & $<0.001$ \\
\hline
\end{tabular}

Abbreviations: SBP systolic blood pressure; DBP diastolic blood pressure; $B M I$ body mass index; FPG fasting plasma glucose; HDL-C high-density lipoprotein cholesterol; $L D L-C$ low-density lipoprotein cholesterol; $T G$ triglyceride

Subsequently, in another cross-sectional cohort of 90 overweight African Americans [33], the TG/HDL-C ratio was tested and the AUC value of the TG/HDL$\mathrm{C}$ ratio to predict IR was 0.56 . Consequently, that study did not support using the TG/HDL-C ratio as a predictor of IR in African Americans, because the relationship between TG/HDL-C and insulin may differ by ethnicities. This result reinforces the motivation of this study.

The Pearson's correlation coefficient showed that the covariates (BMI, WC, FPG, HDL-C, TG and TG/ HDL-C) are all significantly associated with IR (as measured by HOMA-IR) regardless of age. After adjusting for covariates such as age, sex, BMI, current smoking status, HTN, DM, and hyperlipidemia, TG/ HDL-C remained significantly associated with IR (as

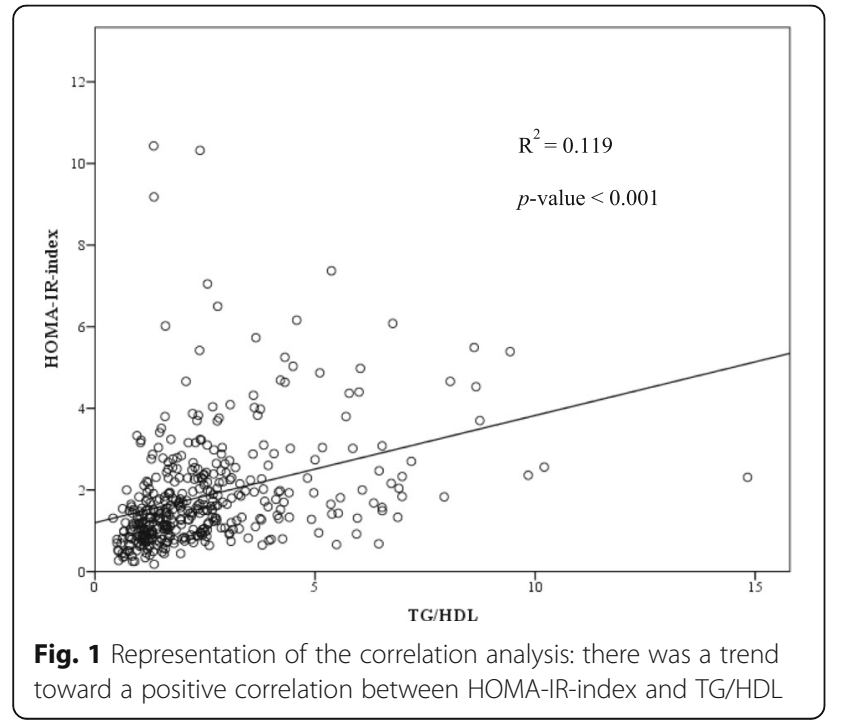

Table 3 Association between TG/HDL levels and HOMA-IR index

\begin{tabular}{|c|c|c|c|}
\hline Variables & Odds ratio & 95\% C.I. & $p$-value \\
\hline \multicolumn{4}{|l|}{ Model 1} \\
\hline Sex (men versus women) & 0.67 & $0.41-1.10$ & 0.11 \\
\hline $\mathrm{TG} / \mathrm{HDL}$ & 1.59 & $1.38-1.83$ & $<0.001$ \\
\hline \multicolumn{4}{|l|}{ Model 2} \\
\hline Sex (men versus women) & 0.59 & $0.34-1.00$ & 0.05 \\
\hline Age (year) & 1.01 & $0.98-1.04$ & 0.52 \\
\hline $\mathrm{BMI}\left(\mathrm{kg} / \mathrm{m}^{2}\right)$ & 1.24 & $1.15-1.34$ & $<0.001$ \\
\hline $\mathrm{TG} / \mathrm{HDL}$ & 1.48 & $1.28-1.72$ & $<0.001$ \\
\hline \multicolumn{4}{|l|}{ Model 3} \\
\hline Sex (men versus women) & 0.59 & $0.34-1.04$ & 0.07 \\
\hline Age (year) & 0.99 & $0.96-1.02$ & 0.58 \\
\hline BMI $\left(\mathrm{kg} / \mathrm{m}^{2}\right)$ & 1.23 & $1.13-1.33$ & $<0.001$ \\
\hline HTN (yes versus no) & 1.88 & $1.11-3.18$ & 0.02 \\
\hline DM (yes versus no) & 5.41 & $2.93-10.01$ & $<0.001$ \\
\hline Hyperlipidemia (yes versus no) & 0.95 & $0.53-1.70$ & 0.85 \\
\hline $\mathrm{TG} / \mathrm{HDL}$ & 1.45 & $1.23-1.72$ & $<0.001$ \\
\hline \multicolumn{4}{|l|}{ Model 4} \\
\hline Sex (men versus women) & 0.64 & $0.36-1.15$ & 0.14 \\
\hline Age (year) & 0.99 & $0.96-1.02$ & 0.51 \\
\hline BMI $\left(\mathrm{kg} / \mathrm{m}^{2}\right)$ & 1.23 & $1.13-1.33$ & $<0.001$ \\
\hline Smoking (yes versus no) & 0.68 & $0.26-1.77$ & 0.42 \\
\hline HTN (yes versus no) & 1.90 & $1.12-3.21$ & 0.02 \\
\hline DM (yes versus no) & 5.44 & $2.93-10.08$ & $<0.001$ \\
\hline Hyperlipidemia (yes versus no) & 0.97 & $0.54-1.74$ & 0.91 \\
\hline TG/HDL & 1.45 & $1.23-1.72$ & $<0.001$ \\
\hline
\end{tabular}

Abbreviations: $B M I$ body mass index; $H D L-C$ high-density lipoprotein cholesterol; TG triglyceride; HTN hypertension; DM diabetes mellitus; $\mathrm{Cl}$ confidence interval 


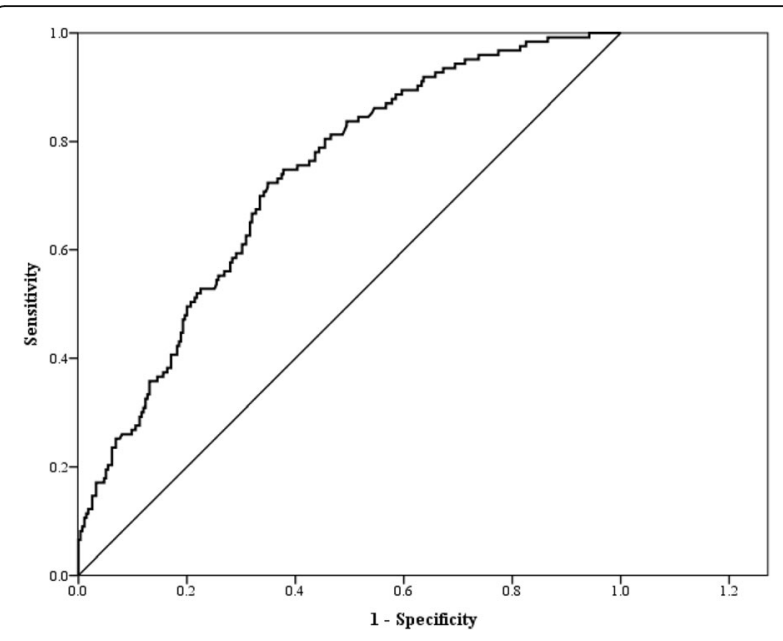

Fig. 2 ROC curve for TG/HDL as a predictor of HOMA-IR index

measured by HOMA-IR) (Table 3). This result reinforces the relationship between IR and TG/HDL-C ratio. Therefore, we suggested that using TG/HDL-C ratio as an index for early identification of IR in middle-aged and elderly Taiwanese.

Several limitations were associated with our study. First, some information that related to IR were not recorded, such as the detail of regular physical exercise and family history of diabetes in the study population. Second, this study was a cross-sectional design that made it difficult for us to explore the causal relationship between TG/HDL-C and IR. Third, the accuracy of the models need additional evaluation when applied to other ethnic groups because ethnicity affects the associations between TG/HDL-C and IR.

\section{Conclusions}

In conclusion, our findings showed that the elevated TG/HDL-C ratio was significantly associated with IR and could be used as an indicator of IR among the middle-aged and elderly population in Taiwan. It is clinically available, thus eliminating any additional costs. Future research is warranted to investigate the use of TG/ HDL-C ratio combined with other risk factors related to IR for predicting IR under diverse ethnic backgrounds.

Table 4 The areas under ROC curve (AUC), sensitivity, specificity by the optimized cut-off points for TG/HDL in predicting HOMA-IR index

\begin{tabular}{llcccc}
\hline Variables & AUC & $p$-value & Cut-off & Sensitivity & Specificity \\
\hline TG/HDL & 0.729 & $<0.001$ & 2.197 & 0.724 & 0.651
\end{tabular}

Abbreviations: $H D L-C$ high-density lipoprotein cholesterol; $T G$ triglyceride; $R O C$ curve receiver operating characteristic curve; $\mathrm{Cl}$ confidence interval

\section{Abbreviations}

ALT: Alanine aminotransferase; BMI: Body Mass Index; BP: Blood pressures; CRP: C-reactive protein; DM: Diabetes mellitus; FPG: Fasting plasma glucose; HDL-C: High-density lipoprotein cholesterol; HOMA-IR: Homeostasis model assessment of insulin resistance; IR: Insulin resistance; LDL-C: Low-density lipoprotein cholesterol; TG: Triglyceride; TG/HDL-C: Triglyceride to highdensity lipoprotein cholesterol; ROC: Receiver operating characteristic; AUC: Area under the ROC curve; HTN: Hypertension; aOR: Adjusted odds ratio; IDF: International Diabetes Federation.; WBC: White blood cell count; WC: Waist Circumference

\section{Acknowledgements}

The authors wish to thank May Lu for her assistance in editing this manuscript and acknowledge the support of the Maintenance Project of the Center for Big Data Analytics and Statistics (Grant CLRPG3D0044) at Chang Gung Memorial Hospital.

\section{Authors' contributions}

WCY wrote the paper, collected the data, designed and performed the analysis. IST and LSC were involved in data collection and analysis. YCT and WCL designed the analysis. JYC contributed data, conceived, designed and performed the experiments. All authors read and approved the final manuscript.

\section{Funding}

This study was supported by Chang Gung Memorial Hospital (grants CORPG3C0171 3C0172, CZRPG3C0053, CORPG3G0021, CORPG3G0022).

\section{Availability of data and materials}

The datasets used and/or analyzed during the current study are available from the corresponding authors upon reasonable request.

\section{Ethics approval and consent to participate}

The study was approved by Chang-Gung Medical Foundation Institutional Review Board (102-2304B), and written informed consent was given by all the participants before enrollment.

\section{Consent for publication}

Not applicable.

\section{Competing interests}

The authors declare that they have no competing interests.

\section{Author details}

${ }^{1}$ Department of Family Medicine, Chang-Gung Memorial Hospital, Linkou Branch, Postal address: No. 5, Fuxing St., Guishan Dist, Taoyuan City 33305, Taiwan, Republic of China. ${ }^{2}$ Chang Gung University College of Medicine, No.259, Wenhua 1st Rd., Guishan Dist., Taoyuan City 333, Taiwan, Republic of China. ${ }^{3}$ Department of Occupational Medicine, Chang Gung Memorial Hospital, Linkou Branch, No.5, Fuxing St., Guishan Dist., Taoyuan City 33305, Taiwan, Republic of China. ${ }^{4}$ Department of Health Management, Xiamen Chang-Gung Hospital, Xiamen, No.123, Xiafei Road, Haicang District, Xiamen, China. ${ }^{5}$ Department of Research, Taipei Tzu Chi General Hospital, Buddhist Tzu Chi Medical Foundation, No.289, Jianguo Rd., Xindian Dist, New Taipei City 23142, Taiwan, Republic of China.

Received: 16 July 2019 Accepted: 30 September 2019

Published online: 11 October 2019

\section{References}

1. Djiogue S, Kamdje AHN, Vecchio L, Kipanyula MJ, Farahna M, Aldebasi Y, Etet PFS. Insulin resistance and cancer: the role of insulin and IGFs. Endocr Relat Cancer. 2013;20:R1-R17.

2. Groop LC. Insulin resistance: the fundamental trigger of type 2 diabetes. Diabetes Obes Metab. 1999;1 (Suppl 1):S1-7.

3. Tenenbaum A, Adler Y, Boyko V, Tenenbaum H, Fisman EZ, Tanne D, Lapidot M, Schwammenthal E, Feinberg MS, Matas Z, et al. Insulin resistance is associated with increased risk of major cardiovascular events in patients with preexisting coronary artery disease. Am Heart J. 2007;153:559-65. 
4. Xia C, Li R, Zhang S, Gong L, Ren W, Wang Z, Li Q. Lipid accumulation product is a powerful index for recognizing insulin resistance in nondiabetic individuals. Eur J Clin Nutr. 2012;66:1035-8.

5. Muniyappa R, Lee S, Chen H, Quon MJ. Current approaches for assessing insulin sensitivity and resistance in vivo: advantages, limitations, and appropriate usage. Am J Physiol Endocrinol Metab. 2008;294:E15-26.

6. DeFronzo RA, Tobin JD, Andres R. Glucose clamp technique: a method for quantifying insulin secretion and resistance. Am J Physiol Endocrinol Metab. 1979;237:E214-23.

7. Keskin M, Kurtoglu S, Kendirci M, Atabek ME, Yazici C. Homeostasis model assessment is more reliable than the fasting glucose/insulin ratio and quantitative insulin sensitivity check index for assessing insulin resistance among obese children and adolescents. Pediatrics. 2005;115:e500-3.

8. Bonora E, Targher G, Alberiche M, Bonadonna RC, Saggiani F, Zenere MB, Monauni T, Muggeo M. Homeostasis model assessment closely mirrors the glucose clamp technique in the assessment of insulin sensitivity: studies in subjects with various degrees of glucose tolerance and insulin sensitivity. Diabetes Care. 2000;23:57-63.

9. Miller WG, Thienpont LM, Van Uytfanghe K, Clark PM, Lindstedt P, Nilsson G, Steffes MW. Toward standardization of insulin immunoassays. Clin Chem. 2009:55:1011-8

10. Lewis GF, Uffelman KD, Szeto LW, Steiner G. Effects of acute hyperinsulinemia on VLDL triglyceride and VLDL apoB production in normal weight and obese individuals. Diabetes. 1993;42:833-42.

11. Van Linthout S, Spillmann F, Schultheiss HP, Tschope C. High-density lipoprotein at the interface of type 2 diabetes mellitus and cardiovascular disorders. Curr Pharm Des. 2010;16:1504-16.

12. McLaughlin T, Reaven G, Abbasi F, Lamendola C, Saad M, Waters D, Simon J, Krauss RM. Is there a simple way to identify insulin-resistant individuals at increased risk of cardiovascular disease? Am J Cardiol. 2005:96:399-404.

13. McLaughlin T, Abbasi F, Cheal K, Chu J, Lamendola C, Reaven G. Use of metabolic markers to identify overweight individuals who are insulin resistant. Ann Intern Med. 2003;139:802-9.

14. Hadaegh F, Hatami M, Tohidi M, Sarbakhsh P, Saadat N, Azizi F. Lipid ratios and appropriate cut off values for prediction of diabetes: a cohort of Iranian men and women. Lipids Health Dis. 2010;9:85.

15. Kannel WB, Vasan RS, Keyes MJ, Sullivan LM, Robins SJ. Usefulness of the triglyceride-high-density lipoprotein versus the cholesterol-high-density lipoprotein ratio for predicting insulin resistance and cardiometabolic risk (from the Framingham offspring cohort). Am J Cardiol. 2008;101:497-501.

16. Di Bonito P, Moio N, Scilla C, Cavuto L, Sibilio G, Sanguigno E, Forziato C, Saitta F, lardino MR, Di Carluccio C, Capaldo B. Usefulness of the high triglyceride-to-HDL cholesterol ratio to identify cardiometabolic risk factors and preclinical signs of organ damage in outpatient children. Diabetes Care. 2012:35:158-62

17. He S, Wang S, Chen X, Jiang L, Peng Y, Li L, Wan L, Cui K. Higher ratio of triglyceride to high-density lipoprotein cholesterol may predispose to diabetes mellitus: 15 -year prospective study in a general population. Metabolism. 2012;61:30-6.

18. Cordero A, Laclaustra M, León M, Casasnovas JA, Grima A, Luengo E, Ordoñez B, Bergua C, Bes M, Pascual I, Alegría E. Comparison of serum lipid values in subjects with and without the metabolic syndrome. Am J Cardiol. 2008:102:424-8

19. Musso C, Graffigna M, Soutelo J, Honfi M, Ledesma L, Miksztowicz V, Pazos M, Migliano M, Schreier LE, Berg GA. Cardiometabolic risk factors as apolipoprotein B, triglyceride/HDL-cholesterol ratio and C-reactive protein, in adolescents with and without obesity: cross-sectional study in middle class suburban children. Pediatr Diabetes. 2011:12:229-34.

20. Zoppini G, Negri C, Stoico V, Casati S, Pichiri I, Bonora E. Triglyceride-highdensity lipoprotein cholesterol is associated with microvascular complications in type 2 diabetes mellitus. Metabolism. 2012;61:22-9.

21. Gaziano JM, Hennekens Charles H, O'Donnell Christopher J, Breslow Jan L, Buring Julie E. Fasting triglycerides, high-density lipoprotein, and risk of myocardial infarction. Circulation. 1997;96:2520-5.

22. Giannini C, Santoro N, Caprio S, Kim G, Lartaud D, Shaw M, Pierpont B, Weiss R. The triglyceride-to-HDL cholesterol ratio: association with insulin resistance in obese youths of different ethnic backgrounds. Diabetes Care. 2011:34:1869-74.

23. Bittner V, Johnson BD, Zineh I, Rogers WJ, Vido D, Marroquin OC, BaireyMerz CN, Sopko G. The triglyceride/high-density lipoprotein cholesterol ratio predicts all-cause mortality in women with suspected myocardial ischemia: a report from the Women's ischemia syndrome evaluation (WISE). Am Heart J. 2009:157:548-55.

24. Li C, Ford ES, Meng Y-X, Mokdad AH, Reaven GM. Does the association of the triglyceride to high-density lipoprotein cholesterol ratio with fasting serum insulin differ by race/ethnicity? Cardiovasc Diabetol. 2008;7:4-4.

25. Quijada Z, Paoli M, Zerpa Y, Camacho N, Cichetti R, Villarroel V, ArataBellabarba G, Lanes R. The triglyceride/HDL-cholesterol ratio as a marker of cardiovascular risk in obese children; association with traditional and emergent risk factors. Pediatr Diabetes. 2008;9:464-71.

26. Fan X, Liu EY, Hoffman VP, Potts AJ, Sharma B, Henderson DC. Triglyceride/ high-density lipoprotein cholesterol ratio: a surrogate to predict insulin resistance and low-density lipoprotein cholesterol particle size in nondiabetic patients with schizophrenia. J Clin Psychiatry. 2011:72:806-12.

27. Bovet $P$, Faeh D, Gabriel A, Tappy $L$. The prediction of insulin resistance with serum triglyceride and high-density lipoprotein cholesterol levels in an east African population. Arch Intern Med. 2006;166:1236-7.

28. Ford ES, Li C, Imperatore G, Cook S. Age, sex, and ethnic variations in serum insulin concentrations among U.S. youth : findings from the National Health and nutrition examination survey 1999-2002. Diabetes Care. 2006;29:260511.

29. Chen L-K, Lin M-H, Chen Z-J, Hwang S-J, Tsai S-T, Chiou S-T. Metabolic characteristics and insulin resistance of impaired fasting glucose among the middle-aged and elderly Taiwanese. Diabetes Res Clin Pract. 2006;71:170-6.

30. Lee CH, Shih AZL, Woo YC, Fong CHY, Leung OY, Janus E, Cheung BMY, Lam KSL. Optimal cut-offs of homeostasis model assessment of insulin resistance (HOMA-IR) to identify dysglycemia and type 2 diabetes mellitus: a 15-year prospective study in Chinese. PLoS One. 2016;11:e0163424.

31. Kolovou GD, Anagnostopoulou KK, Cokkinos DV. Pathophysiology of dyslipidaemia in the metabolic syndrome. Postgrad Med J. 2005;81:358-66.

32. Chiang J-K, Lai N-S, Chang J-K, Koo M. Predicting insulin resistance using the triglyceride-to-high-density lipoprotein cholesterol ratio in Taiwanese adults. Cardiovasc Diabetol. 2011;10:93.

33. Sumner AE, Finley KB, Genovese DJ, Criqui MH, Boston RC. Fasting triglyceride and the triglyceride-HDL cholesterol ratio are not markers of insulin resistance in African Americans. Arch Intern Med. 2005;165:1395-400.

\section{Publisher's Note}

Springer Nature remains neutral with regard to jurisdictional claims in published maps and institutional affiliations.

\section{Ready to submit your research? Choose BMC and benefit from:}

- fast, convenient online submission

- thorough peer review by experienced researchers in your field

- rapid publication on acceptance

- support for research data, including large and complex data types

- gold Open Access which fosters wider collaboration and increased citations

- maximum visibility for your research: over $100 \mathrm{M}$ website views per year

At $\mathrm{BMC}$, research is always in progress.

Learn more biomedcentral.com/submissions 